\title{
Comparison of different strategies on three-dimensional correction of AIS: which plane will suffer?
}

\author{
Tom P. Schlösser ${ }^{1}$ (1) Kariman Abelin-Genevois ${ }^{2}$. Jelle Homans ${ }^{1}$ - Saba Pasha ${ }^{3,4} \cdot$ Moyo Kruyt $^{1}$. Pierre Roussouly ${ }^{2}$. \\ Suken A. Shah ${ }^{5} \cdot$ René M. Castelein ${ }^{1}$
}

Received: 26 July 2020 / Revised: 17 October 2020 / Accepted: 3 November 2020 / Published online: 23 December 2020

(c) The Author(s) 2020

\begin{abstract}
Purpose There are distinct differences in strategy amongst experienced surgeons from different 'scoliosis schools' around the world. This study aims to test the hypothesis that, due to the 3-D nature of AIS, different strategies can lead to different coronal, axial and sagittal curve correction.

Methods Consecutive patients who underwent posterior scoliosis surgery for primary thoracic AIS were compared between three major scoliosis centres $(n=193)$. Patients were treated according to the local surgical expertise: Two centres perform primarily an axial apical derotation manoeuvre (centre 1: high implant density, convex rod first, centre 2: low implant density, concave rod first), whereas centre 3 performs posteromedial apical translation without active derotation. Pre- and postoperative shape of the main thoracic curve was analyzed using coronal curve angle, apical rotation and sagittal alignment parameters (pelvic incidence and tilt, T1-T12, T4-T12 and T10-L2 regional kyphosis angles, C7 slope and the level of the inflection point). In addition, the proximal junctional angle at follow-up was compared.

Results Pre-operative coronal curve magnitudes were similar between the 3 cohorts and improved $75 \%, 70 \%$ and $59 \%$, from pre- to postoperative, respectively $(P<0.001)$. The strategy of centres 1 and 2 leads to significantly more apical derotation. Despite similar postoperative T4-T12 kyphosis, the strategy in centre 1 led to more thoracolumbar lordosis and in centre 2 to a higher inflection point as compared to centre 3. Proximal junctional angle was higher in centres 1 and $2(P<0.001)$ at final follow-up.

Conclusion Curve correction by derotation may lead to thoracolumbar lordosis and therefore higher risk for proximal junctional kyphosis. Focus on sagittal plane by posteromedial translation, however, results in more residual coronal and axial deformity.
\end{abstract}

Keywords Adolescent idiopathic scoliosis · Derotation · Translation · Sagittal alignment

Tom P. Schlösser

t.p.c.schlosser@umcutrecht.nl

Kariman Abelin-Genevois

kgenevois@gmail.com

Jelle Homans

j.f.homans@umcutrecht.nl

Saba Pasha

PashaS@email.chop.edu

Pierre Roussouly

Pierre.Roussouly@croix-rouge.fr

Suken A. Shah

Suken.Shah@nemours.org

René M. Castelein

r.m.castelein@umcutrecht.nl
1 Department of Orthopaedic Surgery, G05.228, University Medical Center Utrecht, P.O. Box 85500, 35084 GA Utrecht, The Netherlands

2 Orthopaedic Department, Centre medico chirurgical Les Massues, Lyon, France

3 Department of Orthopaedic Surgery, The Children's Hospital of Philadelphia (CHOP), Philadelphia, PA, USA

4 The Perelman School of Medicine at the University of Pennsylvania, Philadelphia, PA, USA

5 Department of Orthopaedic Surgery, Nemours/Alfred I. duPont Hospital for Children, Wilmington, DE, USA 


\section{Introduction}

The generally accepted goals of surgery for adolescent idiopathic scoliosis are: avoiding further progression through solid fusion and correction of the deformity into a balanced configuration to restore postural balance $[1,2]$. There is increasing evidence that successful restoration of a harmonious, balanced spine may have a protective effect on the unfused discs, as well as that a critical thoracic kyphosis is required to prevent sagittal plane deterioration and adding on, as well as proximal junctional kyphosis [3-6]. A common problem in posterior thoracic fusion for primary thoracic adolescent idiopathic scoliosis, however, is the flattening effect on the thoracic sagittal profile when derotation and coronal correction are performed [7, 8].

It is well known that AIS is a 3-D deformity of the spine, characterized by rotation, coronal deviation and apical lordosis (Fig. 1) [9-12]. Recently, Acaroglu et al. hypothesized that, due to an intrinsic component of AIS, posterior surgery cannot correct all three planes at the same time [13]. The anterior aspect of the rotated apex is longer than the posterior column in AIS. This length discrepancy is observed in the vertebral bodies, but mostly located in the discs [14]. In an attempt to surgically correct the coronal deviation and axial rotation, the additional anterior length, that has 'escaped' to the side, is rotated back to the midline, creating a thoracic hypokyphosis/lordosis at the level of the apex. The hypothesis by Acaroglu et al. has recently been confirmed by Hershkovitz et al.: They demonstrated that significant correction in the coronal plane is associated with postoperative hypokyphosis [13, 15]. Therefore, less significant coronal or axial correction may be required to achieve more kyphosis restoration.

There are distinct 'schools' for scoliosis surgery around the world with very different surgical strategies. Some surgeons perform primarily an apical axial derotation

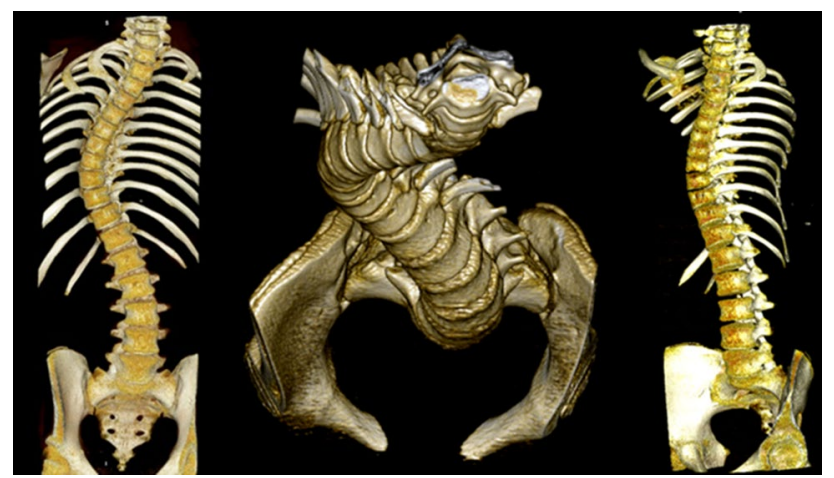

Fig. 13 -D reconstruction of classical thoracic adolescent idiopathic scoliosis, a cranial and frontal view, demonstrating the combination of lateroflexion, lordosis and rotation around the apex of the curvature manoeuvre by different techniques of incremental rod bending and (in)direct vertebral derotation $[7,8,16]$. In contrast, others may focus primarily on the sagittal plane by translation techniques without apical concave instrumentation and avoid active derotation manoeuvres (Figs. 2 and 3). Because each strategy consists of correction manoeuvres that
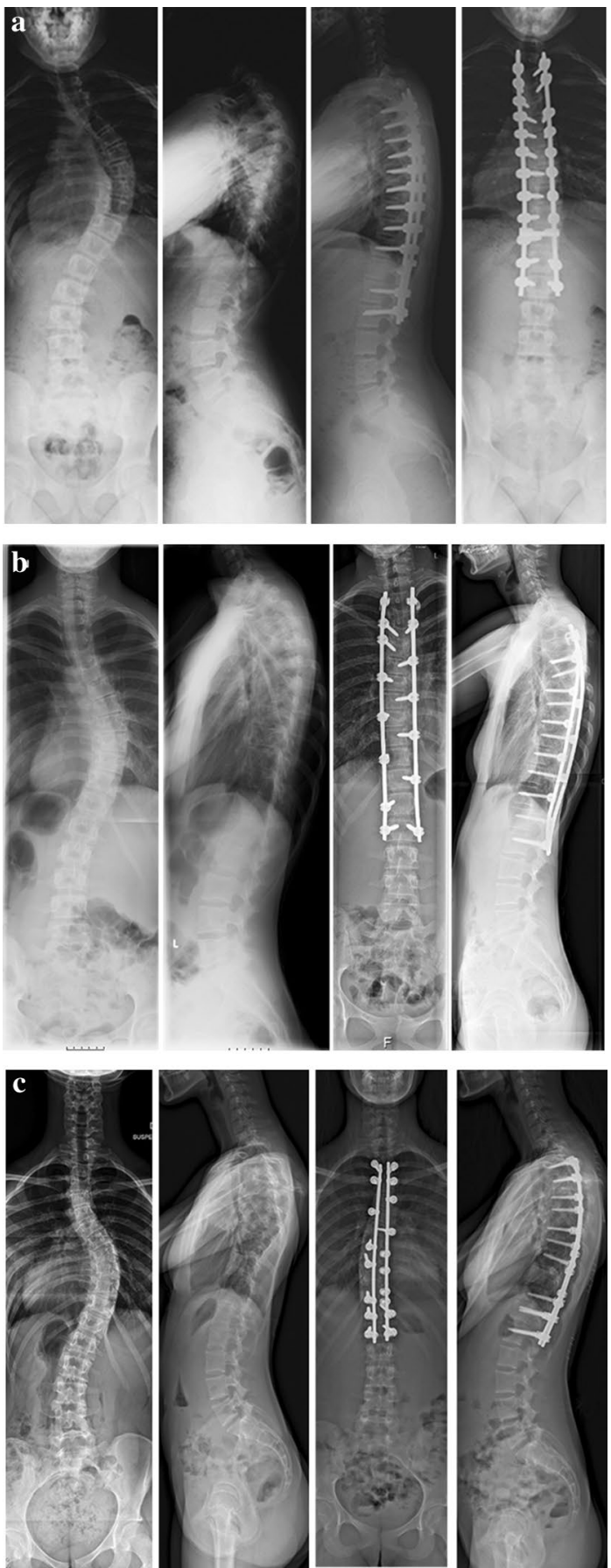

Fig. 2 Three examples of Lenke type 1 curves with a preoperative hypokyphosis that were treated in three scoliosis centres. Postoperative radiographs illustrate the differences in 3-D spinal morphology of the instrumented spine 
Fig. 3 An illustration of the 'philosophy' of the correction manoeuvres performed at each centre. In summary, the centre 3 mostly used a translation manoeuvre for main thoracic curve correction with sometimes concave laminar bands around the apex, whereas centre 1 (high implant density) and centre 2 (low implant density) relied on segmental derotation manoeuvres

primarily provide correction in one plane or the other, different 'schools' make use of different implants and implant densities to achieve their goals. As far as the authors know, to date, no study has directly compared the effect of different strategies on the correction of the coronal, axial and sagittal spinal deformation in AIS.

The aim of this multinational study was to test the hypothesis that different strategies lead to different coronal and sagittal curve correction, and that there is an interaction between the correction of the deformity in the different planes. We retrospectively collected three consecutive cohorts in three major scoliosis centres that have different surgical strategies and evaluated the differences in coronal, axial and sagittal curve correction.

\section{Materials and methods}

\section{Study population}

Three consecutive series of patients who underwent posterior scoliosis surgery for primary thoracic AIS curves were retrospectively collected from three major scoliosis centres in the USA (centre 1), the Netherlands (centre 2) and France (centre 3). Centres were selected based on known differences in the philosophy for correction of the curvatures. All three centres perform more than 100 scoliosis surgeries annually. Patients were treated according to the local surgical expertise by two experienced surgeons per centre and were included if they had biplanar full-spine radiographs available at less than 3 months preoperative (baseline), before hospital discharge (postoperative) and at one or two year follow-up. While in centres 1 and 3, it was standard protocol to radiographically follow patients for at least 24 months postoperative, patients in centre 2 were radiographically followed for 15 months. Gender, age at surgery and the radiographic curve characteristics were recorded (Table 1). Patients with non-idiopathic scoliosis, other spinal pathology, known neural axis abnormalities on MRI, primary lumbar AIS, radiographs without the high thoracic levels visible or previous
Centre 2

Centre 3

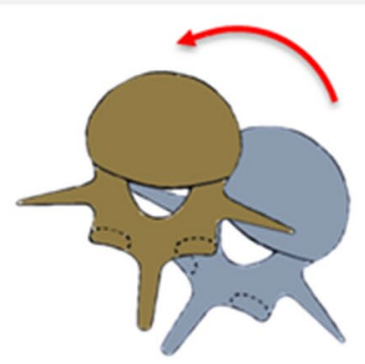

spinal surgery were excluded. This retrospective study was approved by the local institutional review boards.

\section{Surgical cascade}

The local surgeons described the different steps of their strategy in detail according to predefined criteria: use of pre-operative templating, patient positioning, implant type, implant density and implant strategy, ligamentous releases, rod contouring and order of insertion of the rods as well as their surgical technique (Table 1 ). In summary, centres 1 and 2 focused primarily on correcting the coronal and axial plane by different techniques of incremental rod bending and direct vertebral derotation, with pedicle screws around the apex. The difference in strategy between centres 1 and 2 is the implant density and rod insertion technique. Mean implant density was $100 \%$ in centre 1 , and $60 \%$ in centre 2 . Centre 1 started the correction on the convex side, centre 2 at the concave side. On the contrary, the surgeons in centre 3 focus primarily on the sagittal plane by a posteromedial translation technique without apical concave instrumentation and do not use active derotation manoeuvres. Concave laminar bands around the apex were added by one of the surgeons in centre 3 .

\section{Radiographic outcomes}

Similar protocols for radiographic acquisition of digital, plain, full-length lateral radiographs (General Electric AL01F (General Electric, Schenectady, NY, USA); Philips Digital Diagnost (Philips B.V., Best, The Netherlands); Siemens VERTIX (Siemens, Erlangen, Germany); EOS (EOS imaging, SA, Paris, France) were used in the three centres. Acquisition was performed in an upright standing position with the hips, anterior superior iliac spines and shoulders perpendicular to the cassette, subjects were standing with their shoulders in $45^{\circ}$ anteflexion and with their hips and knees straight, and they were instructed to stand in a comfortable manner and to look straight ahead with the hand on the zygoma's or on the clavicles. Conventional coronal, sagittal and axial parameters of the instrumented main thoracic 
Table 1 Comparison of demographics, surgical details and pre- and postoperative sagittal alignment in cohorts of primary thoracic AIS patients in three different countries

\begin{tabular}{|c|c|c|c|c|}
\hline & $\begin{array}{l}\text { Centre } 1 \\
(n=44)\end{array}$ & $\begin{array}{l}\text { Centre } 2 \\
(n=51)\end{array}$ & $\begin{array}{l}\text { Centre } 3 \\
(n=98)\end{array}$ & $P$ \\
\hline \multicolumn{5}{|l|}{ Demographics } \\
\hline Females, $n(\%)$ & $33(75)$ & $41(80)$ & $93(95)$ & $0.002 *$ \\
\hline Age at surgery & $14.4 \pm 1.7$ & $15.5 \pm 2.2$ & $14.5 \pm 1.7$ & $0.005^{*}$ \\
\hline Follow-up in months & $20 \pm 7$ & $15 \pm 7$ & $22 \pm 13$ & $0.002 *$ \\
\hline \multicolumn{5}{|l|}{ Surgical details } \\
\hline Correction technique & $\begin{array}{l}\text { Primarily segmental vertebral } \\
\text { derotation and posterior trans- } \\
\text { lation }\end{array}$ & $\begin{array}{l}\text { Primarily segmental vertebral } \\
\text { derotation }\end{array}$ & $\begin{array}{l}\text { Primarily posteromedial transla- } \\
\text { tion }\end{array}$ & \\
\hline Pre-operative templating & No & No & Yes & \\
\hline Positioning & $\begin{array}{l}\text { Prone on Jackson spine table } \\
\text { with hips and knees } 20-30 \\
\text { degrees flexed and chest pads } \\
\text { mid thoracic }\end{array}$ & $\begin{array}{l}\text { Prone on carbon spine table with } \\
\text { hips and knees } 20-30 \text { degrees } \\
\text { flexed with chest pads mid/high } \\
\text { thoracic }\end{array}$ & $\begin{array}{l}\text { Prone on carbon spine table with } \\
\text { hips } 45 \text { degrees flexed and } \\
\text { knees } 90 \text { degrees flexed and } \\
\text { chest pads mid/low thoracic }\end{array}$ & \\
\hline UIV, mode & $\mathrm{T} 3$ & $\mathrm{~T} 3$ & $\mathrm{~T} 2$ & \\
\hline LIV, mode & L3 & L3 & $\mathrm{L} 2$ & \\
\hline Implant type & Pedicle screws & Hybrid: hooks and screws & $\begin{array}{l}\text { Hybrid: Pedicle screws, hooks } \\
\text { and laminar bands }\end{array}$ & \\
\hline Implant density & High implant density (90-100\%) & Very low implant density $(60 \%)$ & Low implant density $(60-70 \%)$ & \\
\hline Implant strategy & $\begin{array}{l}\text { - Concave mono or uniaxial at } \\
\text { every level } \\
\text { - Convex uniaxial screws at at } \\
\text { least 3-4 apical levels and both } \\
\text { anchors } \\
\text { - UIV: screws }\end{array}$ & $\begin{array}{l}\text { - Bilateral hooks at UIV, } \\
\text { - Bilateral polyaxial pedicle } \\
\text { screws at UIV-1 } \\
\text { - Unilateral, uniaxial pedicle } \\
\text { screws at all other levels }\end{array}$ & $\begin{array}{l}\text { - Apical levels free or laminar } \\
\text { bands at concave side } \\
\text { - Other levels side loading pedi- } \\
\text { cle screws } \\
\text { UIV: screws }\end{array}$ & \\
\hline Posterior ligamentous releases & For rigid curves $>70$ degrees & For rigid curves $>70$ degrees & $\begin{array}{l}\text { Standard treatment at apical } \\
\text { levels }\end{array}$ & \\
\hline Rod contouring & $\begin{array}{l}\text { Overcontoured }\left( \pm 20^{\circ}\right) \text { concave } \\
\text { rod, undercontoured }\left( \pm 20^{\circ}\right) \\
\text { convex road }\end{array}$ & $\begin{array}{l}\text { Overcontoured concave rod } \\
\qquad\left( \pm 20^{\circ}\right) \text {, undercontoured } \\
\left( \pm 20^{\circ}\right) \text { convex road }\end{array}$ & $\begin{array}{l}\text { Slightly overcontoured }\left( \pm 5^{\circ}\right) \\
\text { concave rod, normal convex } \\
\text { rod }\end{array}$ & \\
\hline Rod insertion & $\begin{array}{l}\text { First, concave (cranial to caudal), } \\
\text { second, convex (cranial to } \\
\text { caudal) }\end{array}$ & $\begin{array}{l}\text { First, convex (cranial to caudal), } \\
\text { second, concave (cranial to } \\
\text { caudal) }\end{array}$ & $\begin{array}{l}\text { First, concave (caudal to cranial), } \\
\text { second, convex (cranial to } \\
\text { caudal) }\end{array}$ & \\
\hline
\end{tabular}

curve were measured using dedicated software (Surgimap $®$, Nemaris Inc. ${ }^{\mathrm{TM}}$, New York, NY, USA) by two observers and compared between the three strategies. Differences in pre- and first erect postoperative main thoracic spinal morphology were determined by coronal Cobb angle, axial rotation (Perdriolle method) and sagittal parameters (pelvic incidence, sacral slope, pelvic tilt, Roussouly types for spinopelvic alignment, T1-T12 and T4-T12 kyphosis, T10-L2 sagittal angle, C7 slope, Abelin-Genevois sagittal pattern, level of inflection point) [17]. For comparison of the effect of the different strategies on potential sagittal deterioration, proximal junctional angle (PJA, UIV - UIV + 2) was measured pre-operative and at latest available follow-up.

\section{Statistical analysis}

The statistical analyses were performed using statistical software SPSS 23 for Windows (SPSS Inc., Chicago, IL, USA).
Descriptive statistics were computed for the cohorts, providing means and standard deviations for continuous data, modus for ordinal data, and frequencies and percentages for binominal data. Comparison of demographic and outcome parameters between the different strategies was performed using one-way ANOVA for continuous data and Chi-square for ordinal data. For one-way ANOVA analyses a Bonferroni correction was applied for multiple testing. The level of statistical significance was set at $P<0.05$.

\section{Results}

Demographics of the subjects in the three cohorts are shown in Table 1. Pre- and postoperative radiographic parameters are shown in Table 2. Pre-operative coronal curve magnitudes did not differ between the cohorts. Range of the coronal curve angles were $44-85^{\circ}, 45-94^{\circ}$ and $41-105^{\circ}$, 
Table 2 Preoperative coronal, sagittal and axial alignment in cohorts of primary thoracic AIS patients in three different scoliosis centres

\begin{tabular}{|c|c|c|c|c|}
\hline & $\begin{array}{l}\text { Centre } 1 \\
(n=44)\end{array}$ & $\begin{array}{l}\text { Centre } 2 \\
(n=51)\end{array}$ & $\begin{array}{l}\text { Centre } 3 \\
(\mathrm{n} n=98)\end{array}$ & $P$ \\
\hline \multicolumn{5}{|l|}{ Coronal parameters } \\
\hline MT curve $\left(^{\circ}\right)$ & $\begin{array}{l}58 \pm 12 \\
(43-85)\end{array}$ & $61 \pm 14$ & $60 \pm 14$ & 0.50 \\
\hline MT apex, mode & T6 & $\mathrm{T} 7$ & $\mathrm{~T} 7$ & $0.019 *$ \\
\hline Lenke type 1 or $2, \%$ & $80 \%$ & $66 \%$ & $86 \%$ & $0.004 *$ \\
\hline \multicolumn{5}{|l|}{ Axial parameter } \\
\hline Apical rotation $\left({ }^{\circ}\right)$ & $18 \pm 7$ & $18 \pm 7$ & $18 \pm 6$ & 0.99 \\
\hline \multicolumn{5}{|l|}{ Sagittal parameters } \\
\hline Roussouly type $1, n(\%)$ & $0(0 \%)$ & $0(0 \%)$ & $0(0 \%)$ & 0.07 \\
\hline Roussouly type 2 & $8(18 \%)$ & $13(25 \%)$ & $21(21 \%)$ & \\
\hline Roussouly type $2 \mathrm{AV}$ & $8(18 \%)$ & $10(20 \%)$ & $17(17 \%)$ & \\
\hline Roussouly type 3 & $3(7 \%)$ & $11(22 \%)$ & $27(28 \%)$ & \\
\hline Roussouly type 4 & $25(57 \%)$ & $17(33 \%)$ & $33(34 \%)$ & \\
\hline $\operatorname{PI}\left({ }^{\circ}\right)$ & $51 \pm 13$ & $50 \pm 9$ & $51 \pm 11$ & 0.88 \\
\hline PT & $5 \pm 8$ & $8 \pm 7$ & $9 \pm 7$ & $0.048 *$ \\
\hline SS & $46 \pm 10$ & $42 \pm 7$ & $43 \pm 8$ & 0.06 \\
\hline L1-S1 lordosis & $58 \pm 13$ & $55 \pm 11$ & $50 \pm 11$ & $<0.001$ \\
\hline T10-L2 kyphosis & $-6 \pm 11$ & $1 \pm 7$ & $-1 \pm 9$ & $0.002 *$ \\
\hline T4-T12 kyphosis & $16 \pm 14$ & $23 \pm 8$ & $20 \pm 15$ & $0.036 *$ \\
\hline T1-T12 kyphosis & $24 \pm 14$ & $29 \pm 6$ & $25 \pm 14$ & 0.16 \\
\hline Proximal junctional angle & $3 \pm 6$ & $2 \pm 5$ & $1 \pm 5$ & 0.18 \\
\hline C7 slope & $9 \pm 9$ & $23 \pm 11$ & $17 \pm 10$ & $<0.001 *$ \\
\hline Abelin type 1, n (\%) (normokyphosis) & $16(36 \%)$ & $29(57 \%)$ & $36(37 \%)$ & 0.08 \\
\hline Inflection point, mode & T12-L1 & T12-L1 & T12-L1 & 0.19 \\
\hline
\end{tabular}

$M T$ main thoracic, $P I$ pelvic incidence, $P T$ pelvic tilt, $S S$ sacral slope respectively. In centre 1, 28 were Lenke type 1, 10 type 2 and 6 type 3 . In centre 2, 24 were type 1, 10 type 2, 11 type 3 and 6 type 4 . In centre 3, 60 were type 1, 19 type 2 and 19 type 3 . Radiographs for curve flexibility were obtained in different positions in the participating centres and were therefore not included for comparison.

The strategy of centre 1 (derotation, high implant density, concave rod first) resulted in $75 \%$ coronal curve angle correction, compared to $70 \%$ in centre 2 (derotation, low implant density, convex rod first) and 59\% in centre 3 (posterior translation) (Tables 2 and $3, P<0.001$ ). Apical rotation improved from $18^{\circ}$ to $3^{\circ}, 5^{\circ}$ and $13^{\circ}$ on average in the three centres, respectively. Pre- and postoperative pelvic incidence and Roussouly spinopelvic alignment types did not significantly differ between the cohorts. Patients in centre 1 had significantly larger preoperative T10-L2 lordosis and T4-T12 kyphosis as well as a larger number of hyperkyphotic patients, compared to centres 2 and 3. Despite similar postoperative T4-T12 kyphosis $\left(22.4^{\circ}, 21.7^{\circ}\right.$ vs. $20.6^{\circ}$, respectively), the strategy of centre 3 showed the most harmonious sagittal profile, because the strategy of centre 1 led to significantly more thoracolumbar lordosis $\left(-7 \pm 9^{\circ}\right)$ compared to centre $3(-4 \pm 5)$. The strategy of centre 2 led to a higher inflection point (T11-12) compared to centres 1 and 3 (thoracolumbar junction). At follow-up, PJA was significantly higher and $\mathrm{C} 7$ slope lower in centres 1 and 2 as compared to centre 3 (Tables 2 and $3, P<0.001$ ).

\section{Discussion}

Comparison of the pre- and postoperative shape of the main thoracic curve between three different 'schools' for scoliosis surgery supports the hypothesis that significant coronal and axial correction tends to go at the detriment of the sagittal plane correction, and vice versa [13, 15]. From the AIS pathoanatomy follows that with greater coronal correction and axial derotation, there is relative anterior lengthening of the spine because the apical lordosis is derotated to the midsagittal plane. With limited kyphosis restoration, this could be a contributing factor to sagittal deterioration at the proximal junction of the instrumented spine at late follow-up.

The primary goal of scoliosis surgery has always been to prevent further progression and provide a balanced spine in the coronal and sagittal plane while fusing as few vertebrae as possible. There is evidence, however, that recreating 
Table 3 Postoperative coronal, sagittal and axial alignment in cohorts of primary thoracic AIS patients in three different scoliosis centres

\begin{tabular}{|c|c|c|c|c|}
\hline & $\begin{array}{l}\text { Centre } 1 \\
(n=44)\end{array}$ & $\begin{array}{l}\text { Centre 2 } \\
(n=51)\end{array}$ & $\begin{array}{l}\text { Centre } 3 \\
(n=98)\end{array}$ & $P$ \\
\hline \multicolumn{5}{|l|}{ Coronal parameters } \\
\hline MT curve $\left(^{\circ}\right)$ & $14 \pm 7$ & $18 \pm 8$ & $25 \pm 9$ & $<.0 .001 *$ \\
\hline \multicolumn{5}{|l|}{ Axial parameter } \\
\hline Apical rotation $\left(^{\circ}\right)$ & $3 \pm 3$ & $5 \pm 5$ & $13 \pm 6$ & $<0.001^{*}$ \\
\hline \multicolumn{5}{|l|}{ Sagittal parameters } \\
\hline Roussouly type $1 n, \%$ & $0(0 \%)$ & $0(0 \%)$ & $0(0 \%)$ & 0.11 \\
\hline Roussouly type 2 & $13(30 \%)$ & $21(41 \%)$ & $27(28 \%)$ & \\
\hline Roussouly type $2 \mathrm{AV}$ & $10(23 \%)$ & $6(12 \%)$ & $10(10 \%)$ & \\
\hline Roussouly type 3 & $9(20 \%)$ & $16(31 \%)$ & $38(39 \%)$ & \\
\hline Roussouly type 4 & $12(27 \%)$ & $8(16 \%)$ & $23(23 \%)$ & \\
\hline $\mathrm{PI}\left({ }^{\circ}\right)$ & $49 \pm 12$ & $50 \pm 9$ & $50 \pm 10$ & 0.84 \\
\hline PT & $9 \pm 10$ & $11 \pm 8$ & $10 \pm 7$ & 0.47 \\
\hline SS & $40 \pm 9$ & $38 \pm 8$ & $40 \pm 8$ & 0.41 \\
\hline L1-S1 lordosis & $55 \pm 13$ & $50 \pm 13$ & $50 \pm 10$ & $0.02 *$ \\
\hline T10-L2 kyphosis & $-7 \pm 9$ & $-5 \pm 8$ & $-4 \pm 5$ & $0.047 *$ \\
\hline T4-T12 kyphosis & $22 \pm 6$ & $21 \pm 8$ & $22 \pm 7$ & 0.40 \\
\hline T1-T12 kyphosis & $30 \pm 11$ & $27 \pm 8$ & $28 \pm 8$ & 0.19 \\
\hline C7 slope & $15 \pm 8$ & $14 \pm 5$ & $18 \pm 8$ & $0.002 *$ \\
\hline Abelin type 1 (normokyphosis) & $23(52 \%)$ & $24(47 \%)$ & $55(56 \%)$ & 0.318 \\
\hline Inflection point, mode & T12-L1 & $\mathrm{T} 11-\mathrm{T} 12$ & T12-L1 & $<0.001 *$ \\
\hline \multicolumn{5}{|l|}{ Follow-up parameters } \\
\hline Pelvic tilt & $6 \pm 8$ & $9 \pm 8$ & $9 \pm 8$ & .06 \\
\hline C7 slope & $11 \pm 7$ & $14 \pm 7$ & $16 \pm 7$ & $<0.001 *$ \\
\hline Proximal junctional angle & $6 \pm 7$ & $9 \pm 7$ & $3 \pm 4$ & $<0.001 *$ \\
\hline
\end{tabular}

a normal harmonious spine is beneficial to the remaining, unfused areas of the spine [3-6]. Even with modern day surgical implants, it remains difficult to recreate the normal shape of the adolescent spine and avoid problems like thoracic hypokyphosis and junctional decompensation [7, 8]. For corrective scoliosis surgery, thorough understanding of the three-dimensional pathoanatomy of the deformity could help to overcome the obstacles to reduction.

Lordotic deformation is together with rotation and lateral deviation an integral part of the complex three-dimensional deformity in AIS [9-12, 18]. Scoliosis surgery aims to correct the spinal deformation by combinations of corrections in the six degrees of freedom: translation, derotation and kyphosis restoration [16]. To achieve kyphosis recreation, different posterior releases are often used to allow for lengthening the posterior aspect of the spine. The strategies of centres 1 and 2 mostly relied on segmental derotation manoeuvres with pedicle screws around the apex. Theoretically, derotation of the apical lordosis back to the midline will lead to a compromise in the sagittal plane since it rotates the longer anterior column back to the midline and therefore induces a regional hypokyphosis (Fig. 4) [7, 8]. On the contrary, centre 3 primarily uses a translation manoeuvre, and no active derotation. Recently, concave sub-laminar bands around the apex were added in some patients to aim for more posterior translation of the apical area to recreate physiological global (T4-T12) thoracic kyphosis. This can only be achieved by shortening of the anterior column by compression of the anterior intervertebral discs and/or allowing the longer anterior column to stay deviated laterally and rotated. This technique may lead to a more harmonious sagittal profile by more kyphosis restoration, but leads to less coronal and axial correction.

Factors such as the coronal curve magnitude and flexibility, the use of hooks and implant density have all been implicated in the development of postoperative hypokyphosis. A randomized controlled trial that takes these confounders into account would be optimal to study the outcomes of specific correction strategies. In this retrospective experience-based cohort study, surgeons performed correction techniques in which they have expertise, with their preferred implants and implant strategy. An expertise-based RCT, where patients are not randomized for different treatments by one surgeon, but randomized to surgeons that only deliver the technique in which they have expertise, has been proposed as an alternative for surgical RCT's. Randomization of an AIS patient for surgeons performing their own technique seems theoretically 
Fig. 4 In theory, apical derotation of the intrinsic apical lordosis of the curvature inevitably leads to difficulties in recreating an adequate kyphosis, inadequate inflection point, low C7 angle and therefore higher risk for PJK
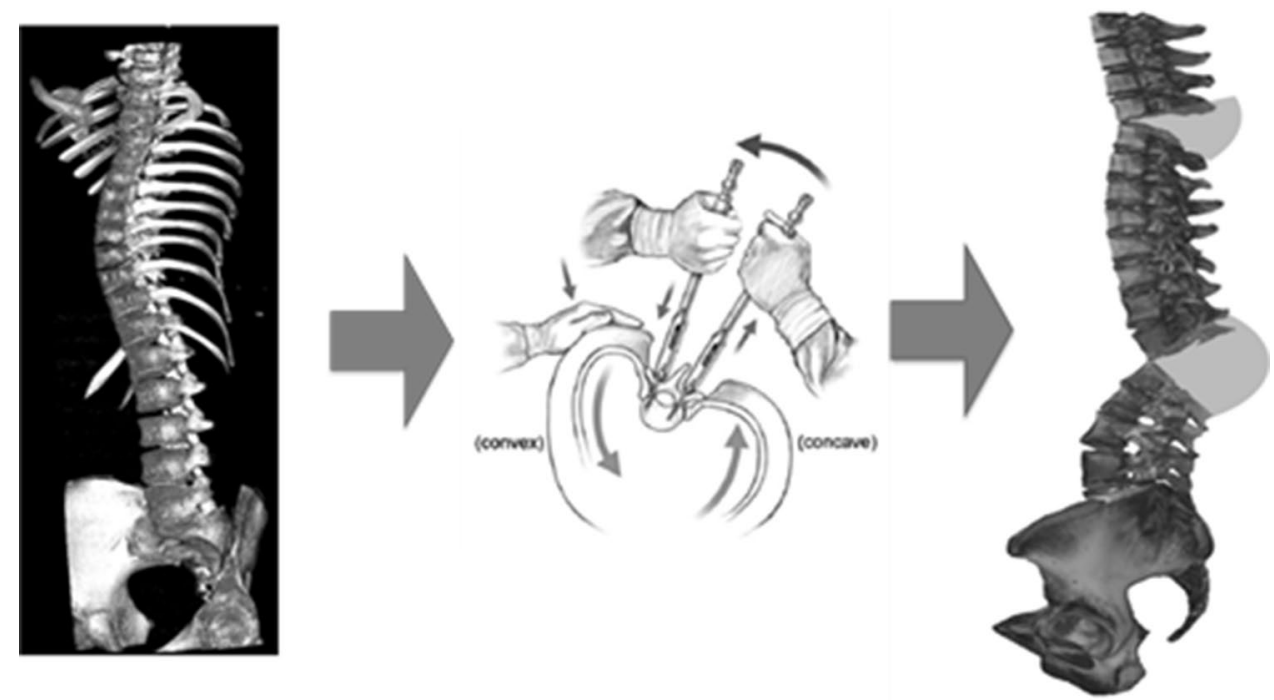

possible, except for the fact that different surgical strategies are often topographically bound.

The aim of this study was not to compare the differences in clinical outcomes of different correction techniques, but to better understand the interaction between the correction of the triplanar deformity in AIS. Recently, Herzkovich et al. demonstrated that focus on correction in the coronal plane is associated with difficulties in restoring normal alignment in the sagittal plane. In the present retrospective study, patients were not matched based on their preoperative sagittal parameters. Preoperatively, the fundamental parameter pelvic incidence and Roussouly spino-pelvic alignment types were comparable between the centres. In centre 1 , however, more patients were hypokyphotic and the mean T10-L2 angle was smaller (more lordosis). The lack of comparability of all preoperative sagittal parameters may give risk of type-1-error and is a limitation of this retrospective study. Postoperatively, we observed that the two centres that primarily use apical derotation experience difficulties in re-creating neutral sagittal alignment of the thoracolumbar junction or inflection point. Despite the preoperative differences, we assume that this could be explained by the effect of derotation. The translation strategy in centre 3 was more successful for the sagittal plane then in the coronal plane correction compared to centres 1 and 2. Long-term radiographic follow-up was not available for all patients, but we observed that the proximal junctional kyphosis angles at standard radiographic follow-up after surgery (15 months to 2 years) were smaller and C7 slope larger in centre 3 . Pelvic tilt remained comparable. The effect of the different strategies on the chest as well as whether the difference in coronal and sagittal plane curve correction has an impact on the clinical outcome for patients cannot be derived from this comparative study and needs further investigation to provide recommendations.
In conclusion, based on comparison of three different 'scoliosis schools', it seems that derotational strategies lead to more coronal and axial correction as compared to a posteromedial translation strategy. Apical derotation, however, inevitably leads to difficulties in re-creating kyphosis in the apical region and may be a risk factor for iatrogenic thoracolumbar lordosis, a non-physiological inflection point, and therefore proximal junctional problems. A posterior and medial translation manoeuvre, however, often results in a sagittal harmonious spine, but significantly less coronal and axial correction. Therefore, in scoliosis surgery, an emphasis on obtaining the best possible result in whichever plane, by the nature of the disorder, automatically leads to a compromise in the other planes. Of course, awareness of this coupling of the outcomes in all three planes has led to modifications of each strategy, mostly sacrificing some correction in the other planes. The effect of extensive releases, implant strategies (such as stronger and stiffer rods) and more emphasis on recreating a patient specific harmonious kyphosis needs to be investigates by modern 3-D imaging techniques that allow for study of the correction of AIS in more detail.

Funding None.

\section{Compliance with ethical standards}

Conflicts of interest None of the authors has any potential conflict of interest

Competing interests One or more of the authors have received or will receive benefits for personal or professional use from a commercial party related directly or indirectly to the subject of this article:

IRB approval This study was reviewed by a local IRB using expedited review. 
Open Access This article is licensed under a Creative Commons Attribution 4.0 International License, which permits use, sharing, adaptation, distribution and reproduction in any medium or format, as long as you give appropriate credit to the original author(s) and the source, provide a link to the Creative Commons licence, and indicate if changes were made. The images or other third party material in this article are included in the article's Creative Commons licence, unless indicated otherwise in a credit line to the material. If material is not included in the article's Creative Commons licence and your intended use is not permitted by statutory regulation or exceeds the permitted use, you will need to obtain permission directly from the copyright holder. To view a copy of this licence, visit http://creativecommons.org/licenses/by/4.0/.

\section{References}

1. Weinstein SL, Dolan LA, Cheng JC, Danielsson A, Morcuende JA (2008) Adolescent idiopathic scoliosis. Lancet 371:1527-1537. https://doi.org/10.1016/S0140-6736(08)60658-3

2. de Kleuver M, Lewis SJ, Germscheid NM, Kamper SJ, Alanay A, Berven SH et al (2014) Optimal surgical care for adolescent idiopathic scoliosis: an international consensus. Eur Spine J 23:2603-2618. https://doi.org/10.1007/s00586-014-3356-1

3. Abelin-Genevois K, Estivalezes E, Briot J, Sevely A, Sales de Gauzy J, Swider P (2015) Spino-pelvic alignment influences disc hydration properties after AIS surgery: a prospective MRI-based study. Eur Spine J 2015(24):1183-1190. https://doi.org/10.1007/ s00586-015-3875-4

4. Akazawa T, Kotani T, Sakuma T, Minami S, Orita S, Fujimoto $\mathrm{K}$ et al (2017) Spinal fusion on adolescent idiopathic scoliosis patients with the level of L4 or lower can increase lumbar disc degeneration with sagittal imbalance 35 years after surgery. Spine Surg Relat Res 1:72-77. https://doi.org/10.22603/ ssrr.1.2016-0017

5. Ilharreborde B (2018) Sagittal balance and idiopathic scoliosis: does final sagittal alignment influence outcomes, degeneration rate or failure rate? Eur Spine J 27:48-58. https://doi.org/10.1007/ s00586-018-5472-9

6. Mimura T, Ikegami S, Oba H, Uehara M, Koseki M, Takahashi J (2019) Factors leading to postoperative pain in adolescent idiopathic scoliosis patients including sagittal alignment and lumbar disc degeneration. Eur Spine J 28:3085-3091. https://doi. org/10.1007/s00586-019-06152-5

7. Hayashi K, Upasani VV, Pawelek JB, Aubin CE, Labelle H, Lenke LG, et al. (2009) Three-dimensional analysis of thoracic apical sagittal alignment in adolescent idiopathic scoliosis. Spine (Phila Pa 1976) 34:792-797. doi: https://doi.org/10.1097/BRS.0b013 e31818e2c36

8. Mladenov KV, Vaeterlein C, Stuecker R (2011) Selective posterior thoracic fusion by means of direct vertebral derotation in adolescent idiopathic scoliosis: effects on the sagittal alignment. Eur Spine J 20:1114-1117. https://doi.org/10.1007/s0058 6-011-1740-7

9. Roaf R (1966) The basic anatomy of scoliosis. J Bone Joint Surg Br 48:786-792

10. Deacon P, Flood BM, Dickson RA (1984) Idiopathic scoliosis in three dimensions. A radiographic and morphometric analysis. J Bone Joint Surg Br 66:509-512

11. Newton PO, Fujimori T, Doan J, Reighard FG, Bastrom TP, Misaghi A (2015) Defining the "Three-Dimensional Sagittal Plane" in Thoracic Adolescent Idiopathic Scoliosis. J Bone Joint Surg Am 97:1694-1701. https://doi.org/10.2106/JBJS.O.00148

12. Schlosser TP, van Stralen M, Chu WC, Lam TP, Ng BK, Vincken KL et al (2016) Anterior overgrowth in primary curves, compensatory curves and junctional segments in adolescent idiopathic scoliosis. PLoS ONE 11:e0160267. https://doi.org/10.1371/journ al.pone. 0160267

13. Acaroglu E, Doany M, Cetin E, Castelein R (2019) Correction of rotational deformity and restoration of thoracic kyphosis are inversely related in posterior surgery for adolescent idiopathic scoliosis. Med Hypotheses 133:109396. https://doi.org/10.1016/j. mehy.2019.109396

14. Schlosser TP, van Stralen M, Brink RC, Chu WC, Lam TP, Vincken KL et al (2014) Three-dimensional characterization of torsion and asymmetry of the intervertebral discs versus vertebral bodies in adolescent idiopathic scoliosis. Spine (Phila Pa 1976). 39:E1159-1166. https://doi.org/10.1097/BRS.000000000000046 7

15. Hershkovich O, D'Souza A, Rushton PRP, Onosi IS, Yoon WW, Grevitt MP (2020) Essential lordosis revisited. Bone Joint J. 102B:513-518. https://doi.org/10.1302/0301-620X.102B4.BJJ-20191069.R1

16. Shah SA (2007) Derotation of the spine. Neurosurg Clin N Am 18:339-345. https://doi.org/10.1016/j.nec.2007.02.003

17. Abelin-Genevois K, Sassi D, Verdun S, Roussouly P (2018) Sagittal classification in adolescent idiopathic scoliosis: original description and therapeutic implications. Eur Spine J 27:21922202. https://doi.org/10.1007/s00586-018-5613-1

18. Pasha S, Hassanzadeh P, Ecker M, Ho V (2019) A hierarchical classification of adolescent idiopathic scoliosis: Identifying the distinguishing features in 3D spinal deformities. PLoS ONE 14:e213406. https://doi.org/10.1371/journal.pone.0213406

Publisher's Note Springer Nature remains neutral with regard to jurisdictional claims in published maps and institutional affiliations. 